\title{
SEBARAN PERMUKIMAN KUNO PADA DAS LAMANDAU DI KAWASAN KALIMANTAN BAGIAN BARAT DAYA: PERSPEKTIF ARKEOLOGI KERUANGAN
}

\section{The Distribution of Old Settlements in Lamandau River Basin in The Southwest Region of Kalimantan: Perspective of Spatial Archaeology}

\author{
Ida Bagus Putu Prajna Yogi ${ }^{1)}$, Sunarningsih ${ }^{1)}$, Vida Pervaya Rusianti \\ Kusmartono"), Citra Iqliyah Darojah ${ }^{2)}$, Gauri Vidya Dhaneswara ${ }^{3)}$ \\ ${ }^{1)}$ Balai Arkeologi Provinsi Kalimantan Selatan \\ Jalan Gotong Royong II, RT 03/06, Banjarbaru 70711, Kalimantan Selatan, Indonesia \\ ${ }^{2)}$ Perkumpulan Ahli Arkeologi Indonesia Komisariat Daerah Daerah Istimewa \\ Yogyakarta Jawa Tengah \\ Jalan Raya Solo - Yogyakarta No.15, Keniten, Tamanmartani, Daerah Istimewa \\ Yogyakarta, Indonesia \\ ${ }^{3)}$ Dinas Kebudayaan dan Pariwisata Provinsi Kalimantan Tengah. \\ Jalan Tjilik Riwut, Km. 5. Palangka Raya, Indonesia \\ e-mail: idabagus.prajna@kemdikbud.go.id (Coresponding Author)
}

Naskah diterima: 20-01-2021 - Revisi terakhir: 08-06-2021

Disetujui terbit: 25-06-2021 - Tersedia secara online: 30-06-2021

\begin{abstract}
The archaeology potential in Lamandau river basin has not been intensively explored. The ancient settlement is one of the interesting archaeological facts to be studied in this area. This study aims to understand the pattern of macro distribution of ancient settlements in $S$ Lamandau river basin. By understanding the distribution patterns of ancient settlements, it is expected to provide a reference for local wisdom in adapting to the environment, selecting residential locations, and building vernacular architecture. Therefore, this study used a spatial archeology approach on a macro scale. Research results showed that laterally (spatial), the distribution of ancient settlements in Lamandau river basin was divided into three regions, i.e. downstream; middle stream; and upstream Vertically (time), the oldest settlement occurred in the upper reaches of Lamandau river, while the most recent one is in around the area of middle stream. The characteristics of multicomponent site were identified to be located in the lower and midstream parts of Lamandau river basin, which contain the most complex findings.
\end{abstract}

Keywords: Lamandau River Basin; Riverine Culture; Distribution of Ancient Settlements; Spatial Archaeology; Characteristic of Settlement

\footnotetext{
Abstrak

Potensi arkeologi pada daerah aliran Sungai Lamandau belum dieksplorasi secara intensif. Permukiman kuno adalah salah satu potensi arkeologi yang menarik untuk diteliti di kawasan ini. Penelitian ini bertujuan untuk memahami pola sebaran permukiman kuno secara makro pada daerah aliran Sungai Lamandau. Pemahaman terhadap pola sebaran permukiman kuno diharapkan dapat memberikan rujukan tentang kearifan lokal dalam beradaptasi dengan lingkungan, pemilihan lokasi permukiman, serta pembangunan arsitektur vernacular. Oleh karena itu, penelitian ini menggunakan pendekatan arkeologi keruangan dalam skala makro. Hasil penelitian menunjukkan
} 
bahwa secara lateral (keruangan), sebaran permukiman kuno pada daerah aliran Sungai Lamandau terbagi menjadi tiga bagian, yaitu hilir, pertengahan, dan hulu. Secara vertikal (temporal), permukiman kuno dari periode tertua berada di bagian hulu Sungai Lamandau, sedangkan permukiman yang paling muda ada di kawasan pertengahan sungai. Adapun karakteristik multicomponent site diidentifikasi berada di bagian hilir dan pertengahan daerah aliran sungai Lamandau, yang mengandung temuan paling kompleks.

Kata kunci: Daerah Aliran Sungai Lamandau; budaya sungai; Archaeological Macro Spatial Settlement; karakteristik permukiman

\section{PENDAHULUAN}

Pada masa lalu sungai memegang peranan penting, terutama sebagai prasarana transportasi dan komunikasi antardaerah dan antarnegara. Kelancaran tersebut berimbas pada proses pembentukan permukiman di sepanjang daerah aliran sungai, yang bermuara pada pembentukan pusat pemerintahan (politik) dan perdagangan (ekonomi) serta munculnya budaya sungai (riverine culture) masyarakat pendukungnya (Yogi 2017). Daerah aliran sungai (DAS) atau daerah tangkapan air dalam istilah asing disebut catchment area, river basin, atau watershed ialah suatu kawasan daratan yang topografinya dibatasi oleh punggung-punggung bukit yang menampung dan menyimpan air hujan untuk kemudian disalurkan dalam bentuk aliran permukaan, aliran bawah permukaan, aliran bawah tanah ke sungai, dan akhirnya bermuara ke danau atau laut. Kawasan daratan tersebut memiliki suatu ekosistem dengan unsur utamanya berupa sumber daya alam (tanah, air, dan vegetasi), dan unsur tambahan sumber daya manusia sebagai agen pemanfaat sumber daya alam (Hamidah, Setiawan, dan Marfai 2016).

Luas permukiman masa lalu bergantung dari banyak faktor. Ukuran permukiman dari masa ke masa dapat semakin luas atau semakin sempit (Demjan dan Dreslerova 2016). Kesamaan bentuk dan gaya dalam perwujudan budaya material di suatu permukiman merupakan ukuran batasan wilayah suatu kekuasaan atau organisasi terpusat pada kala itu. Paling tidak ada kontak yang intensif antarpermukiman dan pasti terjadi pertukaran (Knappett 2012; Whitelaw et al. 1997; Sbonias 2012; Wilson dan Day 2000; Driessen 2001; Haggis 2002; Schoep 1999; Relaki 1999). Kondisi politik pada suatu masa dapat memengaruhi distribusi permukiman pada suatu wilayah (Spencer dan Bevan 2018).

Studi pola permukiman yang berkembang adalah (1) studi yang memusatkan perhatian pada struktur individual suatu permukiman, seperti rumah atau bangunan tertentu; (2) studi yang memberikan perhatian pada permukiman lokal, seperti suatu desa, dan (3) studi yang mengarahkan perhatian pada pola-pola permukiman di suatu kawasan, misalnya pada suatu kawasan DAS atau lembah (Ahimsa-Putra 1997).

Penelitian ini secara administratif dilakukan di dua wilayah kabupaten, yaitu Kabupaten Lamandau dan Kabupaten Kota Waringin Barat (Gambar 1). DAS Lamandau merupakan kawasan yang sarat dengan kandungan nilai kesejarahan dan unik dengan beragam kebudayaan yang berlanjut hingga kini. Keberlanjutan kebudayaan di kawasan tersebut didukung oleh keharmonisan hubungan antara berbagai etnis yang berdiam di kawasan tersebut, terutama masyarakat Dayak sebagai penduduk tertua dan 
masyarakat pendatang seperti Banjar, Jawa, Bugis dan Cina. Kitab Negarakertagama (1365) juga menyebutkan bahwa Kutaringin (penyebutan pada masa lalu) adalah salah satu daerah tributary Majapahit (Mulyana 1979).

Penelitian arkeologi di bagian hilir DAS Lamandau sudah dilakukan beberapa kali. Lima tim penelitian sudah melakukan pendataan, yaitu tiga kali survei oleh tim dari Pusat Arkeologi Nasional pada 1993, 1994 dan 1995 (Nasruddin 1994; Fadillah 1994; Harkantiningsih dan Kusmartono 1995) dan dua kali survei oleh tim dari Balai Arkeologi Banjarmasin pada 2007 dan 2014 (Hartatik 2009; Tim Peneliti 2014). Mohammad Ali Fadillah dalam tesisnya Etude Archeo-Historique sur L'etat, Les Cites Les Commerce en Indonesie: Le Cas de Kotawaringin au Sud-Ouest de Borneo menunjukkan peranan situs-situs penting pada periode Islam yang berkaitan dengan eksistensi Kerajaan Kotawaringin abad ke-17--19 Masehi. Situs-situs tersebut termasuk Kotawaringin Lama, Sungai Rangas, Pendulangan, Pangkalan Bun, Kumai, Sukamara, Parit Cina Asam, dan Parit Cina Maabu Pangkat (Harkantiningsih dan Kusmartono 1995).

Penelitian oleh Pusat Penelitian Arkeologi Nasional di wilayah Kotawaringin Barat (Muara DAS Arut dan DAS Lamandau) pada tahun 1994 menunjukkan bahwa daerah ini mempunyai peran yang lebih banyak pada masa sejarah, terutama masa Islam. Hal ini dibuktikan dengan banyaknya peninggalan masa Islam, seperti istana atau keraton, masjid-masjid, dan makam tokoh-tokoh penyiar agama Islam. Peninggalan dari masa prasejarah relatif sedikit. Salah satu peninggalan dari masa prasejarah berupa nekara perunggu, sekarang disimpan di keraton Kesultanan Astana Alnusari di Kotawaringin Lama. Asal nekara tersebut tidak diketahui, tetapi menurut tipologinya, nekara memiliki unsur budaya Dong Son yang berasal dari daerah Vietnam (Nasruddin 1994).

Mohammad Ali Fadillah (1994) menyimpulkan bahwa situs Kotawarangin Lama tidak dapat diragukan lagi sebagai bekas Ibu kota Kerajaan Kotawaringin. Namun demikian, sebelumnya situs tersebut sudah menjadi situs habitasi kelompok masyarakat prakerajaan Islam. Dalam penelitian tersebut, hasil analisis kontekstual terhadap temuan arkeologi menimbulkan masalah baru berkaitan dengan pola permukiman masa prakerajaan Islam (Fadillah 1994).

Penelitian oleh Balai Arkeologi Banjarmasin pada tahun 2007 berupa eksplorasi kontinuitas budaya dari prasejarah hingga kolonial di Kotawaringin Barat di bagian Muara Sungai Lamandau dan Arut. Penelitian tersebut menunjukkan bahwa Kotawaringin Barat mempunyai objek dan situs yang beragam, tetapi situs dari masa prasejarah dan klasik belum ditemukan. Sisa-sisa aktivitas budaya pada masa klasik (Hindu-Buddha) berupa temuan arca Buddha di Situs Sungai Rangas-Sebuai dan temuan-temuan lepas yang merupakan koleksi keturunan Kerajaan Kotawaringin, seperti arca perunggu Dewi Sri dan arca Dewa Indra, arca Dewi Tara, Çiwa, dan Ganesha. Beberapa keramik yang ditemukan di Sungai Rangas-Sebuai berasal dari Cina masa Dinasti Tang, Yuan, Ming, dan Qing (Hartatik 2009). 
Pada tahun 2014 Balai Arkeologi Banjarmasin bekerja sama dengan Dinas Kebudayaan dan Pariwisata Kabupaten Kotawaringin Barat melakukan survei potensi situs di DAS Arut dan dokumentasi koleksi keramik di rumah Mangkubumi dan Astana Alnursari. Hasil survei menunjukkan adanya peninggalan arkeologi di muara Sungai Lamandau, yaitu di Desa Sebuai dan Dusun Pendulangan; kedua situs tersebut telah direkam pada survei terdahulu oleh Pusat Penelitian Arkeologi Nasional. Hasil survei 2014 berupa informasi adanya temuan artefak dari Desa Sebuai, di tiga lokasi yang berbeda, yaitu 1) keramik asing di sekitar kantor kepala desa, 2) bata, nisan kubur Islam dan keramik asing di Natai Bata, dan 3) keramik asing dan tiang rumah di Sambuk (Tim Peneliti 2014).

Konsentrasi temuan keramik asing dan mata uang Cina juga ditemukan di Dusun Pendulangan. Berdasarkan hasil analisis terhadap keramik asing dari situs-situs di muara DAS Lamandau tersebut dapat diketahui bahwa peninggalan sebagian besar merupakan keramik Cina (Dinasti Song Akhir dan Yuan) dan Vietnam, yang berasal dari abad ke-13--14 M (Tim Peneliti 2014). Keberadaan temuan keramik asing mengindikasikan adanya aktivitas perdagangan pada masa lalu di tempat tersebut. Karakteristik situs yang berada di Desa Sebuai dan Dusun Pendulangan adalah hunian di pesisir yang berlanjut.

Mohammad Ali Fadillah (1994) dalam laporannya memaparkan bahwa terdapat inskripsi berangka tahun pada akhir abad ke-14 M yang menyebutkan pedagang Cina berlabuh di Kao-to Lingyin (Kotawaringin) dengan melayari Shung-ai Ma-chiao (Sungai Lamandau). Informasi tersebut dapat menjadi petunjuk bahwa Kotawaringin merupakan salah satu tujuan para pedagang Cina di Nusantara. Hasil penelitian yang sudah dilakukan tersebut masih menyisakan banyak pertanyaan, terutama pada pola hunian dan pertanggalan situs secara absolut. Demikian juga dengan perannya dalam kegiatan perdagangan di masa lalu, belum dapat diketahui. Keberadaan DAS Lamandau di wilayah tersebut telah menjadi akses kawasan penting bagi tumbuh dan berkembangnya Kerajaan Islam Kotawaringin, bahkan kehidupan pada masa sebelumnya.

Berdasarkan latar belakang tersebut, permasalahan yang diajukan pada penelitian ini adalah identifikasi keruangan setiap situs pada lanskap DAS Lamandau (Gambar 1). Hasil identifikasi tersebut ditujukan untuk memahami pola sebaran permukiman kuno secara makro pada DAS Lamandau. Kebaharuan penelitian ini ialah mengenai potensi Permukiman Kuno di DAS Lamandau yang sebelumnya belum pernah dilakukan. Pola sebaran permukiman kuno tersebut diharapkan dapat memberikan kontribusi pada 1) pemahaman perilaku adaptasi lingkungan, baik dalam pemanfaatan sumber daya alam maupun bertahan terhadap kondisi alam. Kearifan lokal yang dapat dipetik dari perilaku tersebut adalah pemilihan arsitektur vernacular yang selaras dengan lingkungannya; 2) pemahaman masyarakat pada masanya dalam pemilihan lokasi permukiman. Pemilihan lokasi permukiman dalam suatu ruang tertentu dapat merefleksikan perilaku dan kearifan lokal masyarakat pada masa lampau dalam memenuhi aspek sosioekonominya. 




Gambar 1. Peta Lokasi Penelitian (Sumber: Dokumen Balai Arkeologi Kalimantan Selatan, 2019).

\section{METODE}

Penelitian ini menggunakan penalaran induktif, yaitu data yang disajikan bersifat kualitatif. Pendekatan yang digunakan adalah arkeologi keruangan (spatial archaeology) (Tan 2010). Kajian arkeologi ini dalam operasionalnya berusaha untuk mempelajari persebaran data arkeologi dan hubungannya dengan keruangan berdasarkan data primer yang diperoleh melalui penelitian di lapangan. Tingkatan skala mikro mempelajari persebaran dan hubungan lokasional antara benda-benda arkeologi dalam suatu bangunan atau fitur. Skala meso mempelajari sebaran dan hubungan lokasional antara artefak-artefak serta fitur-fitur dalam suatu situs, sedangkan skala makro mempelajari sebaran dan hubungan lokasional antara benda-benda arkeologi serta situs-situs pada suatu wilayah (Clarke 1977). 
Teknik pengumpulan data di lapangan dilakukan dengan metode survei, ekskavasi, wawancara, dan pemetaan (Renfrew dan Bahn 2012; Simanjuntak 2008). Survei dilakukan untuk mengidentifikasi sebaran temuan arkeologis secara horizontal, sedangkan ekskavasi dilakukan untuk mendapatkan data arkeologi secara vertikal. Wawancara dilakukan untuk mengumpulkan data dari masyarakat yang berkaitan dengan situs yang diteliti, seperti cerita rakyat dan informasi tentang berbagai macam artefak yang pernah ditemukan dan lingkungan mereka. Kegiatan pemetaan dilakukan untuk membuat plotting sebaran situs. Pola dari sebaran permukiman dapat diketahui dengan menggunakan analisis arkeologi keruangan dengan melihat keletakan sebaran permukiman kuno tersebut pada peta jalur Sungai DAS Lamandau, dengan titik berat pada dimensi ruang daripada dimensi bentuk dan waktu (Mundardjito 2002).

\section{HASIL DAN PEMBAHASAN}

\section{Permukiman-Permukiman Kuno di DAS Lamandau Bagian Hulu}

Permukiman kuno di bagian hulu DAS Lamandau terbentuk sebagai kompleks hunian dengan masyarakat pendukung yang sumber penghidupannya bergantung pada alam. Karakteristik tinggalan arkeologi yang merupakan bekas permukiman kuno di hulu DAS Lamandau selalu ditandai dengan hadirnya batu pemanggul laman (Gambar 2). Batu pemanggul laman ialah satu atau lebih batu alam yang diletakkan di lokasi tertentu ketika di lokasi tersebut akan didirikan suatu kampung atau permukiman. Batu pemanggul laman hampir selalu ditemukan pada bekas permukiman kuno yang sudah ditinggalkan ataupun permukiman kuno yang masih dihuni oleh masyarakat pendukungnnya hingga sekarang.

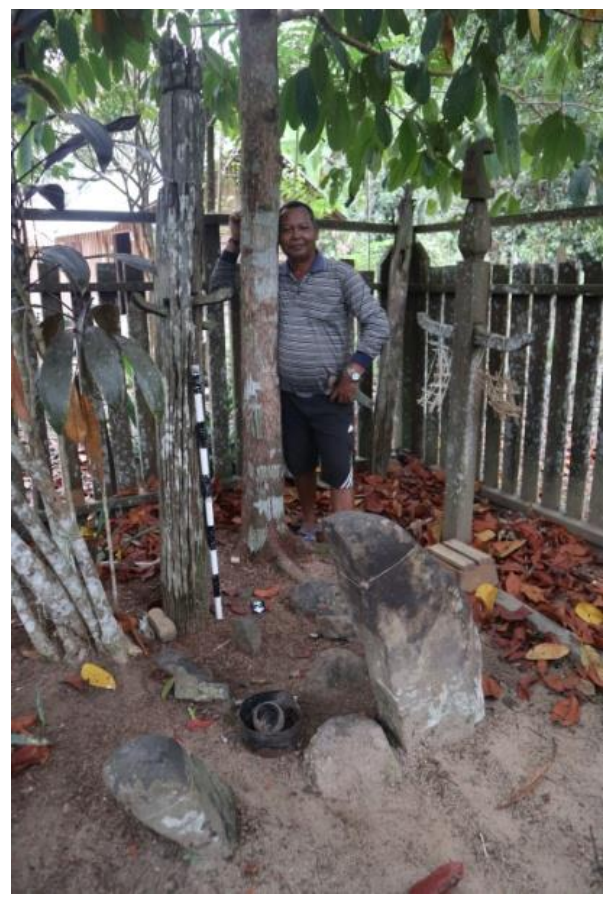

Gambar 2. Batu Pamanggul Laman (Sumber: Dokumen Balai Arkeologi Kalimantan Selatan, 2019). 
Permukiman kuno di kawasan hulu DAS Lamandau di dalamnya memiliki komponen bangunan masa lalu yang masih bertahan dan difungsikan hingga saat ini (living monument). Bangunan tersebut berupa bangunan rumah tinggal (Gambar 3), jurunk (lumbung padi) (Gambar 4) dan beberapa banguanan makam tradisonal yang disebut Sadung (Gambar 5). Pada beberapa bekas permukiman kuno juga ditemukan pola pembagian ruang yang menjadikan orientasi rumah tinggal tidak hanya menghadap ke sungai, tetapi manghadap ke jalan-jalan kampung tersebut.

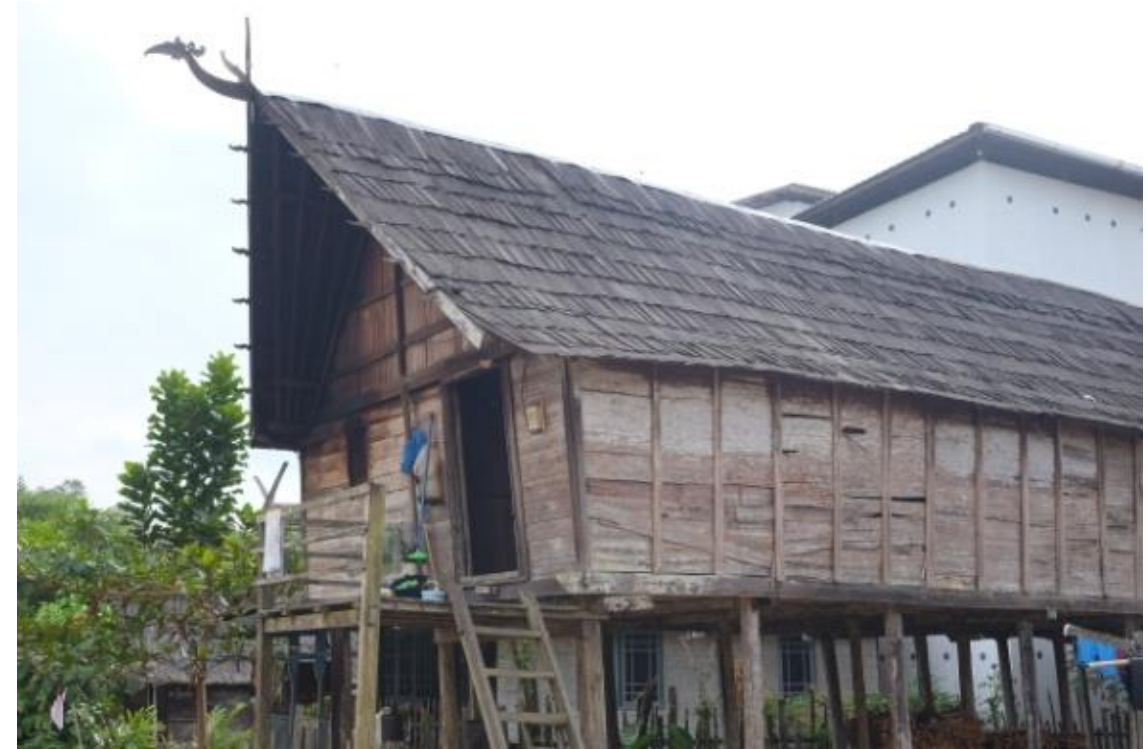

Gambar 3. Rumah Tradisional Masyarakat Dayak Tomun (Sumber: Dokumen Balai Arkeologi Kalimantan Selatan, 2019).

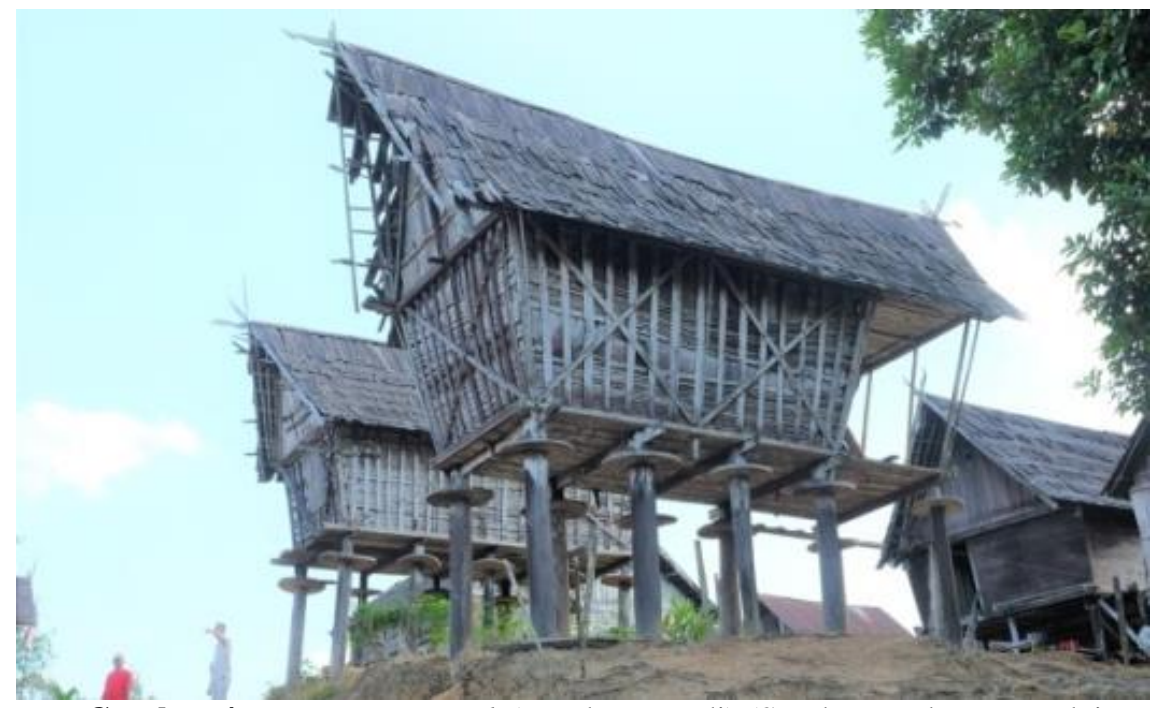

Gambar 4. Bangunan Jurunk (Lumbung Padi) (Sumber: Dokumen Balai Arkeologi Kalimantan Selatan, 2019). 


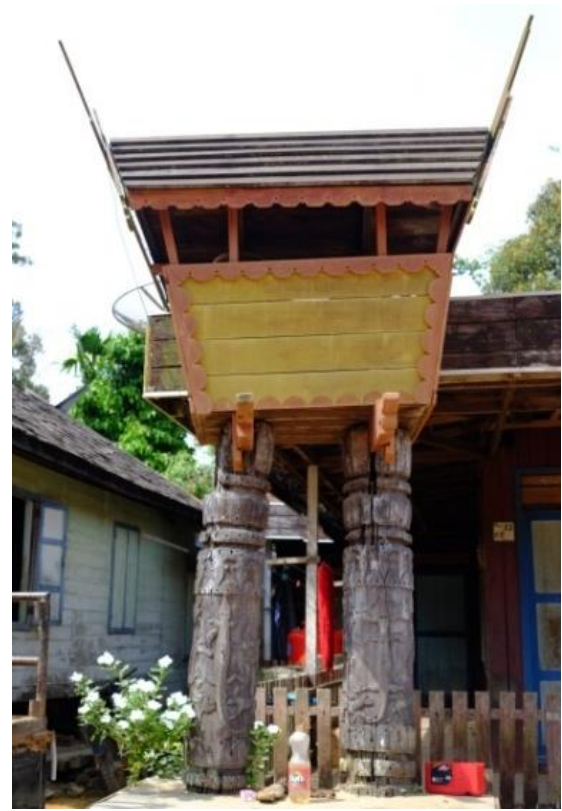

Gambar 5. Salah Satu Bentuk Sandung (Bangunan Kubur Sekunder) di Hulu DAS Lamandau (Sumber: Dokumen Balai Arkeologi Kalimantan Selatan, 2019).

Hampir semua komponen bangunan dan struktur pada permukiman tua di hulu dibuat dari bahan kayu. Rumah merupakan bangunan panggung bertiang setinggi empat meter dari dasar tanah. Sumber daya kayu yang melimpah dari hutan primer di pedalaman Kalimantan menyebabkan masyarakat dengan mudah mengambil bahan bangunan pada masa lalu. Kayu yang digunakan untuk membangun hunian kebanyakan adalah ulin atau dikenal juga dengan kayu besi (Eusideroxylon zwageri), yang spesiesnya bermacam-macam. Kayu ulin yang terkenal kuat, bahkan mampu bertahan lebih dari 500 tahun adalah jenis kayu ulin matahari (istilah lokal). Hasil analisis pertanggalan karbon C14 diperoleh usia tertua dari sampel tiang kayu ulin salah satu rumah tradisonal diperoleh pertanggalan $\pm 550 \mathrm{BP}$.

Di setiap lokasi bekas permukiman kuno dan permukiman kuno yang masih dihuni oleh masyarakat pendukungnya selalu ditemukan artefak keramik dalam kondisi pecah atau fragmentaris. Keramik-keramik tersebut dikumpulkan beberapa dan dilakukan analisis bentuk dan bahan. Keramik tertua yang ditemukan adalah keramik Cina dari Dinasti Song dan keramik yang termuda adalah produk Eropa yang berasal dari akhir abad ke-19 M. Keramik yang ditemukan berupa keramik wadah dan nonwadah. Keramik wadah berupa buli-buli, tempayan, mangkuk, piring, sendok, dan fragmen teko. Benda keramik nonwadah yang ditemukan berupa patung-patung keramik berukuran kecil.

Pada permukiman kuno yang saat ini masih dihuni oleh masyarakat pendukungnya secara berkelanjutan, ditemukan suatu model permukiman dengan pola ruang khusus. Desa Kinipan menjadi salah satu contoh permukiman kuno yang memiliki pola pembagian ruang di area perkampungannya. Berdasarkan komponennya, bangunan rumah tinggal selalu dilengkapi dengan bangunan jurunk (lumbung padi). Hal 
tersebut menunjukkan karakteristik hunian masyarakat yang bermata pencaharian sebagai peladang. Mereka menanam padi ladang atau tadah hujan pada lereng-lereng perbukitan di sepanjang kanan kiri aliran Sungai Batang Kawa, yang merupakan anak Sungai Lamandau.

Situs yang mengindikasikan aktivitas peleburan juga ditemukan di beberapa lokasi di bagian hulu DAS Lamandau. Aktivitas pengelolaan besi mulai dari menambang sumber bahan hingga proses peleburannya pada masyarakat hulu DAS Lamandau, dikenal dengan istilah meurau atau me-ngurau. Tinggalan arkeologi yang ditemukan dari aktivitas peleburan ini berupa tuyer atau lubang angin dari tungku peleburan. Indikator aktivitas peleburan besi paling banyak terdapat di Desa Karang Bosi pada Sungai Belantikan, anak Sungai Lamandau.

\section{Permukiman Kuno di Bagian Pertengahan Aliran DAS Lamandau}

Kotawaringin Lama terletak pada induk Sungai Lamandau, yaitu sekitar 80 km dari muara sungai. Tinggalan arkeologi yang ditemukan di permukiman urban ini cukup kompleks, terutama dari periode Islam. Bangunan bekas keraton masa Islam yang sekarang dikenal sebagai Astana Al Nusari memiliki komponen masjid (Gambar 6) dan makam. Hal tersebut menunjukan bahwa wilayah ini dahulu menjadi pusat pemerintahan. Karakteristik perkotaan pada periode Islam pun sangat tampak pada pusat kedatuan ini.

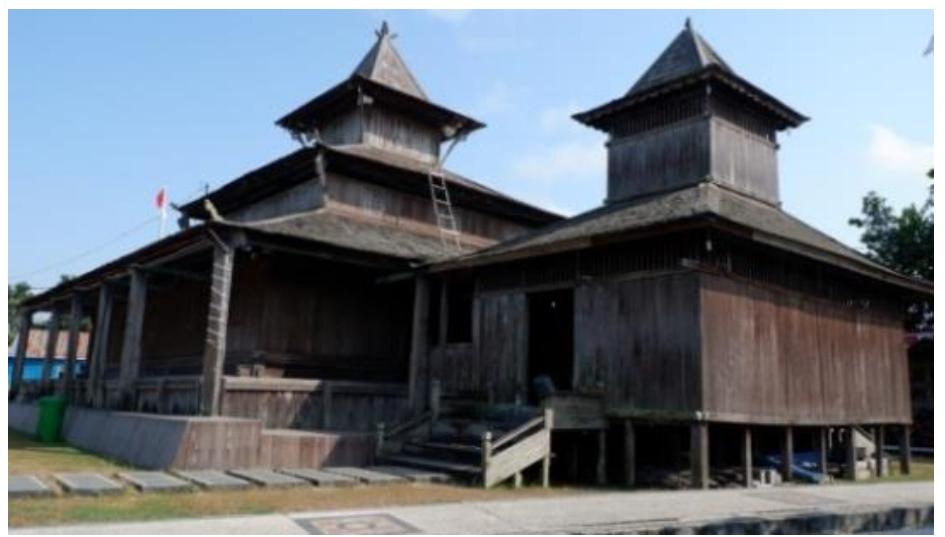

Gambar 6. Masjid Kyai Gede (Sumber: Dokumen Balai Arkeologi Kalimantan Selatan, 2019).

Indikasi pengaruh Hindu yang disebutkan di Negarakretagama tentang nama Kutaringin di kawasan DAS Lamandau kemungkinan terletak di Kota Waringin Lama. Dalam kompleks keraton banyak dijumpai pohon beringin dan dikisahkan bahwa lokasi pusat Kutaringin periode Hindu tersebut banyak ditumbuhi pohon beringin. Pada salah satu pohon beringin di dalam kompleks keraton pernah ditemukan arca dewi yang dibuat dari batu andesit. Berdasarkan langgamnya, arca tersebut diperkirakan berasal dari abad ke-14 M (Gambar 7). Selain itu, dijumpai pula suatu inskripsi angka tahun pada gondang, semacam bedug dengan ukuran lebih panjang dan berdiameter lebih kecil, Masjid Kyai Gede di Situs Kota Waringin Lama yang menyuratkan ...i 1356 saniscara (1434 M) (Gambar 8). 


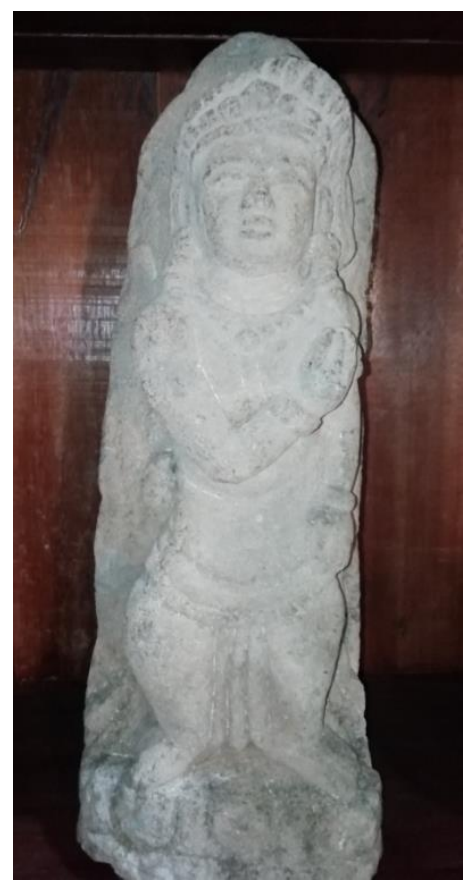

Gambar 7. Temuan Arca Dewi di Istana Alnusari Kotawaringin (Sumber: Dokumen Balai Arkeologi Kalimantan Selatan, 2019).

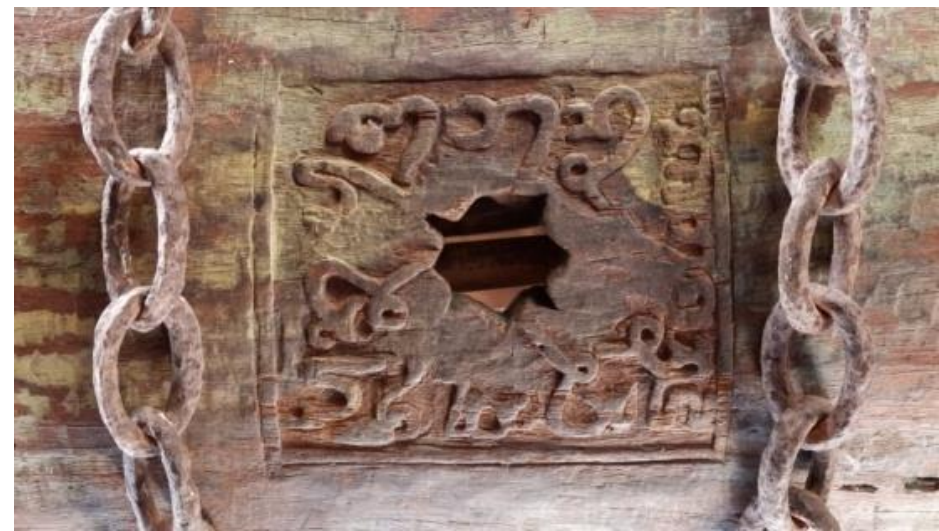

Gambar 8. Inskripsi Angka Tahun di Gondang Masjid (Sumber: Dokumen Balai Arkeologi Kalimantan Selatan, 2019).

Kotawaringin Lama walaupun berada di bagian pertengahan sungai yang agak jauh dari muara DAS Lamandau, diperkirakan bahwa sejak abad ke-14 hingga awal abad ke-19 M sudah menjadi permukiman urban yang memiliki peran sebagai pusat pemerintahan dan pusat kontrol ekonomi di dua sistem DAS, yaitu DAS Lamandau dan DAS Arut. Walapun pusat pemerintahan dan politiknya di Kotawaringin Lama, bandar dagangnya terletak di sekitar Pendulangan di muara sungai (Gambar 9).

Berbeda dengan Kotawaringin Lama, permukiman tua di Nanga Bulik yang letaknya di posisi pertengahan (midstream) jalur sungai, data mengenai arkeologi yang menunjukkan indikasi permukiman kuno di daerah Nanga Bulik lebih sedikit 
ditemukan. Permukiman di Nanga Bulik baru muncul pada periode Islam sekitar abad ke-18 M. Permukiman tersebut merupakan kompleks hunian yang didirikan oleh keluarga Kerajaan Kotawaringin Islam, yaitu Pangeran Kertawana. Permukiman tersebut adalah salah satu kompleks hunian kuno di Nanga Bulik yang berada di tepi aliran Sungai Lamandau. Semula permukiman tersebut berbentuk kampung di tepi sungai yang terdiri atas sebelas rumah keluarga.

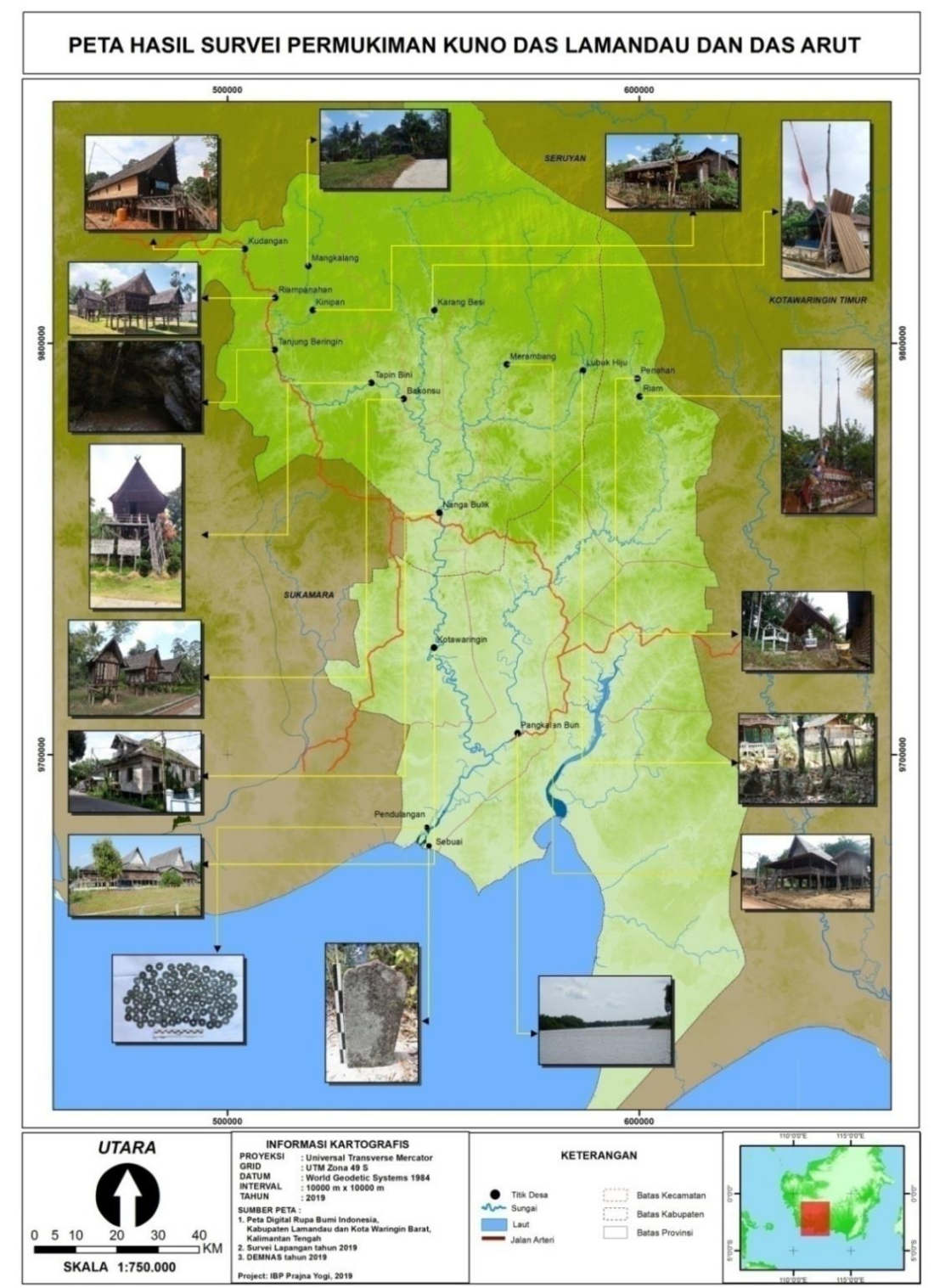

Gambar 9. Peta Sebaran Makro Permukiman Kuno di DAS Lamandau dan Arut (Sumber: Dokumen Balai Arkeologi Kalimantan Selatan, 2019).

Pada masa selanjutnya, pemukim beragama Kristen dari Kapuas mulai datang ke Nanga Bulik (pada masa itu Nanga Bulik masih masuk dalam wilayah onderdristik Lamandau). Agama Kristen masuk ke Nanga Bulik dari wilayah Kapuas atau Buntoi melalui Zending Basel. Tinggalan arkeologi yang mengindikasikan aktivitas Zending pada masa lalu masih tampak hingga kini. Bangunan rumah pendeta dan beberapa 
bangunan yayasan kesehatan yang didirikan oleh Zending masih tampak berdiri di Nanga Bulik (Gambar 10).

Permukiman pertengahan di DAS Lamandau tumbuh sebagai kelompok hunian yang berfungsi sebagai pengontrol sistem Sungai Lamandau di periode ini menjadi Ibu Kota Kota Lamandau. Nanga Bulik merupakan wilayah pertemuan beberapa anak Sungai Lamandau. Posisi Nanga Bulik memang jauh dari muara sungai, tetapi karena kawasan ini merupakan titik pertemuan beberapa anak sungai Lamandau, Nanga Bulik kemudian lebih memiliki peran dalam aktivitas pertukaran komoditas sebagai titik pertemuan anak Sungai Lamandau di bagian hulu dengan permukiman di hilir.

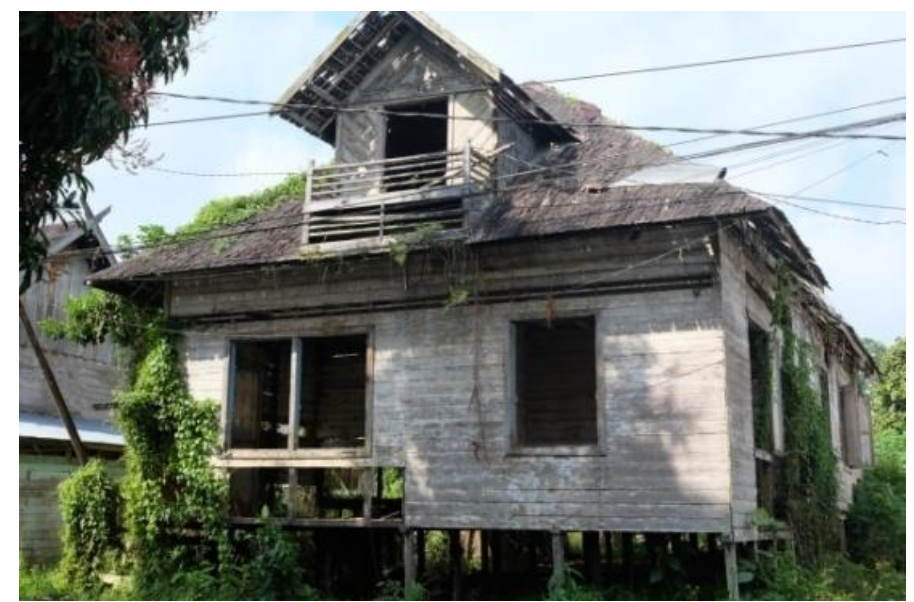

Gambar 10. Rumah Pendeta Zending di Nanga Bulik (Sumber: Dokumen Balai Arkeologi Kalimantan Selatan, 2019).

\section{Permukiman Kuno di Bagian Hilir DAS Lamandau}

Bekas permukiman kuno pada bagian hilir DAS Lamandau ditemukan di beberapa lokasi. Lokasi dengan temuan cukup banyak ialah di Desa Pendulangan dan Desa Sebuai. Berdasarkan data artefak berupa keramik dan mata uang yang ditemukan di kedua lokasi bekas permukiman tersebut diperoleh kronologi masa berkisar dari abad ke-13 hingga ke-14 M. Hasil penelitian menunjukkan bahwa hunian di situs tersebut berkelanjutan, tidak hanya mewakili periode tertentu. Untuk sementara ini, masa tertua permukiman adalah abad ke-13--14 M, yaitu masa kerajaan besar Majapahit di Jawa bagian timur sedang berkuasa. Pengaruh Majapahit diidentifikasi pula dari sumber tertulis Negarakertagama yang menyebutkan hubungan aktivitas perdagangan melalui laut yang ramai terjadi pada sekitar abad ke-13--14 M (Munandar 2011). Inskripsi angka tahun pada gondang Masjid Kyai Gede menjadi sebuah data yang menunjukkan terjadinya kontak dengan Jawa pada periode tersebut.

Berita Cina dari Shun Feng Hsiang Shung, sekitar akhir abad ke-15 M, mencatat pelayaran pedagang Cina yang berlabuh di Kao-to Lingyin (Kotawaringin) dengan melayari Shung-ai Ma-chiao (Sungai Lamandau), Dengan demikian, tidak mustahil kronik tersebut dapat membuktikan bahwa Kotawaringin merupakan salah satu tempat tujuan para pedagang Cina di Kepulauan Indonesia (Fadillah 1994). Situs di pesisir 
tersebut tampaknya sangat berkaitan dengan aktivitas perdagangan dengan daerah luar, terutama impor komoditas keramik asing dari Cina dan Vietnam (Gambar 11). Selain itu, ada kemungkinan muara dan DAS Lamandau telah menjadi pelabuhan pada masa kerajaan Hindu atau dengan kata lain sebagai pusat aktivitas perdagangan. Temuan keramik di Desa Sebuai dan Desa Pendulangan tidak berada pada satu titik saja, tetapi tersebar di empat lokasi yang berbeda. Setiap lokasi mempunyai perbedaan, baik dari segi kedekatan dengan tepi laut maupun topografinya. Di situs Pendulangan banyak ditemukan kepeng Cina dari abad ke-13 M (Gambar 12).
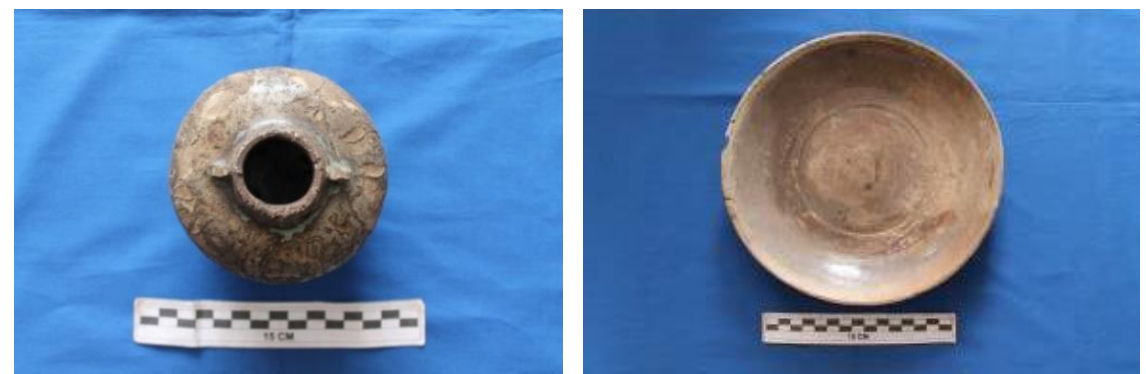

Gambar 11. Buli-buli dari Situs Sebuai, Periode Dinasti Yuan 1271--1368 M dan Piring keramik Vietnam Abad ke-13--14 M di Situs Sebuai (Sumber:

Dokumen Balai Arkeologi Kalimantan Selatan, 2014).
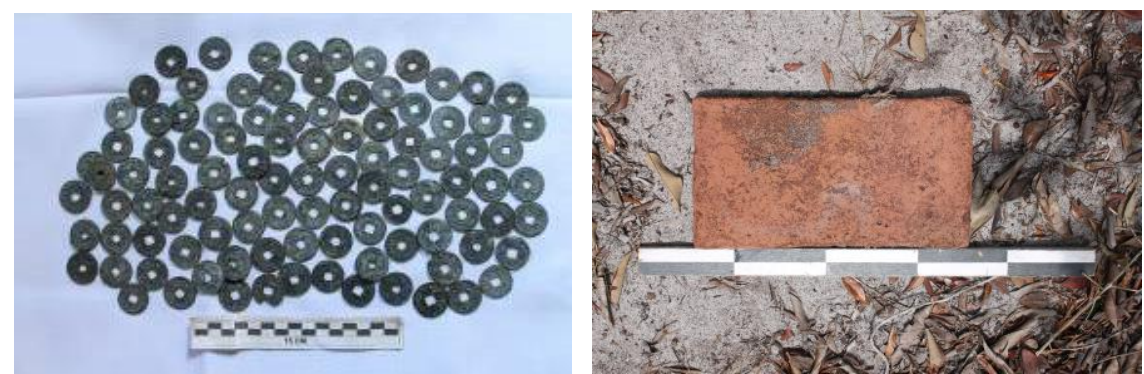

Gambar 12. Kepeng Cina (Mata Uang Cina) Abad ke-13 M dan Bata, Temuan di Situs Pendulangan (Sumber: Dokumen Balai Arkeologi Kalimantan Selatan, 2014).

Permukiman kuno yang berada di muara Lamandau ini merupakan permukiman dengan lingkungan basah pasang surut. Permukiman kuno yang ditemukan ini ada yang berorientasi pada sungai, ada juga yang jauh dari sungai dan linier mengikuti garis pantai. Pada permukiman kuno ini terdapat sebaran bata yang ukuran berkisar $30 \mathrm{x} 18$ $\mathrm{cm}$ dan bentuknya menyerupai bata-bata yang ditemukan di Trowulan dari era Majapahit (Gambar 12).

Permukiman ini kemungkinan bermula sebagai tempat bertemunya pedagang dari luar dan masyarakat dari kawasan lebih hulu untuk melakukan pertukaran komoditas. Dalam perkembangannya kemudian tempat ini menjadi suatu pelabuhan dagang, tetapi tidak bertahan lama. Berdasarkan data arkeologi yang ditemukan, permukiman ini menjadi kompleks hunian yang ramai dan didukung oleh masyarakat yang heterogen, tetapi bertahan sekitar satu abad. Ada kemungkinan pada periode 
berikutnya permukiman ini tetap ada, tetapi pusat perdagangan atau politik pada sistem sungai ini sudah berpindah lokasi.

\section{Sebaran Permukiman Kuno di DAS Lamandau}

Permukiman kuno pada DAS Lamandau muncul dan berkembang kemungkinan berkaitan dengan mata pencaharian sebagai aktivitas pemenuhan kehidupan masyarakatnya. Jika masyarakatnya mengandalkan sektor perdagangan atau pertukaran, mereka akan memilih permukiman yang strategis berdasarkan akses transportasi atau titik pertemuan. Hal tersebut tampak pada DAS Lamandau yang menunjukkan keberadaan permukiman-permukiman kuno mulai bagian muara sungai hingga bagian pertengahan DAS Lamandau.

Permukiman-permukiman tersebut aktif mengadakan aktivitas pertukaran dengan permukiman lainnya. Bahkan, di beberapa lokasi pernah menjadi pusat kontrol politik dan ekonomi pada masa lalu. Permukiman-permukiman yang menjadi pusat perdagangan dan kontrol politik kemudian tumbuh dan berkembang menjadi kawasan urban.

Permukiman kuno di bagian hulu DAS Lamandau memiliki hunian-hunian yang tidak hanya muncul dan berkembang di persimpangan sungai. Masyarakat di bagian hulu sejak masa lalu hingga sekarang bermata pencaharian sebagai peladang dan memanfaatkan hasil hutan. Dengan demikian, permukiman mereka tumbuh di lokasilokasi yang dekat dengan lahan subur untuk berladang dan hutan yang memiliki sumber daya alam melimpah.

Jika mengacu pada teori dendritik oleh Bronson (1977), DAS Lamandau termasuk sungai yang memiliki pola aliran dendritik sehingga mengakibatkan pertumbuhan permukiman dan kegiatan perdagangan linier yang mengikuti aliran sungai. Menurut teori dendritik, permukiman yang dianggap sebagai pusat kegiatan perdagangan berada di muara sungai (Bronson 1977). Kawasan muara sebagai pengontrol pintu gerbang lalu lintas barang, manusia, dan juga kebudayaan teraba (tangible) dan takteraba (intangible) yang menyertainya.

Jaringan sungai sama pentingnya dengan jalan darat. Para penguasa wilayah berusaha untuk menguasai seluruh sistem sungai yang ada di dalam wilayah kekuasaannya agar dapat menguasai hegemoni politik. Kontrol wilayah dilakukan dengan menguasai muara sungai karena tidak mungkin untuk mengontrol seluruh sistem sungai yang ada. Walaupun wilayah dapat dikuasai, penguasa tidak mudah untuk melakukan kontrol ekonomi secara langsung terhadap penduduk yang bermukim di hulu sungai serta di luar DAS untuk saling berinteraksi dengan pendatang. Oleh karena itu, biasanya penguasa di wilayah mengandalkan kekuatan fisik dan pembentukan aliansi untuk menguasai daerah pedalaman (Hall 1985).

Melalui pengontrolan terhadap muara sungai dimungkinkan untuk dapat memengaruhi pergerakan naik turunnya sistem sungai. Penguasa muara sungai dapat menggunakan kontrolnya terhadap jaringan komunikasi sungai untuk membentuk berbagai aliansi dengan kelompok-kelompok yang berada di hulu sungai (Hall 1985). 
Permukiman di bagian muara dan pertengahan muncul di masa berikutnya dari waktu ke waktu. Indikasi permukiman kuno di DAS Lamandau memang tampak pada data arkeologi mulai dari hulu hingga hilir sungai. Mengenai detail peran dan aktivitas kehidupan masa lalu di setiap permukiman, kiranya diperlukan penelitian yang lebih fokus pada setiap permukiman.

\section{PENUTUP}

Data mengenai permukiman kuno DAS Lamandau tersebar mulai dari kawasan hilir sungai hingga kawasan hulu sungai. Permukiman di bagian hulu Lamandau merupakan permukiman awal yang muncul lebih dahulu jika dibandingkan degan permukiman di daerah pertengahan DAS atau di bagian hilir DAS. Permukiman di bagian hulu lebih sering mengalami perpindahan pada periode awalnya atau mereka bermukim tetap dan membangun pondok sementara selama masa bercocok tanam di ladang. Hal tersebut disebabkan pendukung budaya permukiman bermata pencaharian berladang, berpindah, atau hidup berburu hewan di hutan.

Permukiman di bagian pertengahan DAS, yaitu antara Kawasan hulu dan hilir sungai, merupakan permukiman yang muncul lebih belakangan jika dibandingkan dengan permukiman di hulu dan hilir. Permukiman pertengahan pada DAS Lamandau tumbuh sebagai permukiman urban pada periode sekarang yang kemudian menjadi ibu kota pemerintahan dan pusat perdagangan. Lokasi Nanga Bulik yang terletak di sekitar pertengahan DAS Lamandau merupakan kawasan bertemunya beberapa anak sungai Lamandau. Posisi Nanga Bulik memang jauh dari muara sungai, tetapi karena wilayah ini merupakan titik pertemuan beberapa anak sungai, Nanga Bulik kemudian lebih memiliki peran jika dibandingkan dengan permukiman di bagian hilirnya.

Pada abad ke-14 hingga ke-19 Masehi, permukiman yang tumbuh menjadi pusat kontrol ekonomi pada DAS Lamandau ialah Kota Waringin. Letak Kota Waringin jauh dari kawasan muara DAS ini. Keletakan Kota Waringin dalam sistem sungai tidak hanya memegang peranan pada DAS Lamandau. Namun, kuasa Kota Waringin pada periode Hindu dan Islam tersebut meliputi dua wilayah DAS, yaitu DAS Lamandau dan DAS Arut.

Daerah paling muara merupakan kawasan pusat pertukaran antara kawasan luar sungai dengan kawasan di bagian hulu sungai. Kontrol politik dan penguasa tidak berada tepat di muara sungai. Kontrol penguasa yang diperkirakan mulai tumbuh pada kisaran awal abad ke-14 Masehi berada di kawasan hulu Sungai Lamandau, tepatnya di Kuta Waringin.

Permukiman kuno di DAS Lamandau ini ditemukan datanya mulai dari bagian hilir hingga Hulu DAS Lamandau. Hal tersebut disebabkan kawasan aliran sungai yang panjang dan jumlah anak sungai yang tersebar ke beberapa kawasan hinterland Kalimantan yang luas. Permukiman di bagian hulu muncul dan berkembang di lokasi yang memang potensial sebagai daerah hunian bagi masyarakat yang bermata pencaharian sebagai peladang dan hidup berburu. 


\section{DAFTAR PUSTAKA}

Ahimsa-Putra, Heddy Shri. 1997. "Arkeologi Permukiman; Asal Mula dan Perkembangnnya." Jurnal Humaniora V: 15-25.

Bronson, B. 1977. "Exchange in the Upstream and Downstream Ends: Notes Towards a Functional Model of the Coastal State in Southeast Asia." In Economic Exchange and Social Interaction in Southeast Asia: Perspectives From Pre-History and Ethnography Ann Arbor., diedit oleh Karl Hutterer, 39-52. Michigan: Center for South and Southeast Asian Studies University of Michigan.

Clarke, David L. 1977. "Spatial Analysis in Archaeology”, Spatial Archaeology. London, New York, San Fransisco: Academic Press.

Demjan, Peter, dan Dagmar Dreslerova. 2016. "Modelling Distribution of Archaeological Settlement Evidence Based on Heterogeneous Spatial and Temporal Data." Journal of Archaeological Science 6: 100-109.

Driessen, J. 2001. "History and hierarchy. preliminary observations on the settlement pattern of minoancrete." In Urbanism in the Aegean Bronze Age (Sheffield Studies in Aegean Archaeology), diedit oleh K. Branigan, 51-71. London: Sheffield Academic Press.

Fadillah, Mohammad Ali. 1994. "Laporan Penelitian Arkeologi Kotawaringin 1994." Jakarta: Pusat Penelitian Arkeologi Nasional.

Haggis, D. 2002. "Integration and Complexity in the Late Prepalatial Period. A view from the Countryside in Eastern Crete." In Labyrinth Revisited: Rethinking Minoan Archaeology, diedit oleh Y. Hamilakis, 120-142. Oxford: Oxbow Books.

Hall, Kenneth R. 1985. Maritime Trade and State Development in Early Souteast Asia. Honolulu: University of Hawaii Press.

Hamidah, Noor R., Rijanta Bakti Setiawan, dan Muhammad Aris Marfai. 2016. “Analisis Permukiman Tepian Sungai yang Berkelanjutan, Kasus Permukiman Tepian Sungai Kahayan Kota Palangkaraya.” Jurnal Inersia XII (1): 13-24.

Harkantiningsih, M. Th. Naniek, dan Vida R. Kusmartono. 1995. "Survei Eksploratif Arkeologi di Provinsi Kalimantan Tengah”. Laporan Penelitian Arkeologi. Banjarmasin: Balai Arkeologi Banjarmasin.

Hartatik. 2009. "Kontinuitas Budaya di Kabupaten Kotawaringin Barat, Kalimantan Tengah." Berita Penelitian Arkeologi 3 (1).

Knappett, C. 2012. "A Regional Network Approach to Protopalatial Complexity." In Back to the Beginning: Reassessing Social and Political Complexity on Crete during the Early and Middle Bronze Age, diedit oleh I. Schoep, P. Tomkins, dan J. Driessen, 384-402. Oxford: Oxbow Books.

Mulyana, Slamet. 1979. Nagarakretagama dan Tafsir Sejarahnya. Jakarta: Bhratara Karya Aksara.

Munandar, Agus Aris. 2011. Catuspatha Arkeologi Majapahit. Jakarta: Wedatama Widya Sastra.

Mundardjito. 2002. Pertimbangan Ekologis Penempatan Situs Masa Hindu-Budha di Daerah 
Yogyakarta. Jakarta: Wedatama Widya Sastra dan École française d'Extrême-Orient.

Nasruddin. 1994. "Laporan Penelitian Arkeologi Kotawaringin Barat, Kalimantan Tengah." Banjarmasin.

Relaki, Maria. 1999. "The Social Arenas of Tradition. Investigating Collective and Individual Social Strategies in the Prepalatial and Protopalatial Mesara." In Back to the Beginning Reassessing Social and Political Complexity on Crete During The Early And Middle Bronze Age, diedit oleh Ilse Schoep, Peter Tomkins, dan Jan Driessen, 290-324. Oxford: Oxbow Books.

Renfrew, Colin, dan Paul Bahn. 2012. Archaeology: Theories, Methods and Practicele. London: Thames \& Hudson.

Sbonias, K. 2012. "Regional elite-groups and the production and consumption of seals inthe Prepalatial period. A case-study of the Asterousia region." In Back to the Beginning: Reassessing Social and Political Complexity during the Early and Middle Bronze Age, diedit oleh Ilse Schoep, Peter Tomkins, dan Jan Driessen, 273-289. Oxford: Oxbow Books.

Schoep, Ilse. 1999. "Tablets and Territories? Reconstructing Late Minoan IB Political Geography through Undeciphered Documents." American Journal of Archaeology 103 (2): 201-221. https://doi.org/10.2307/506745.

Simanjuntak, H.T. dkk. 2008. Metode Penelitian Arkeologi. Jakarta: Pusat Penelitian Arkeologi Nasional.

Spencer, Christine., dan Andrew Bevan. 2018. "Settlement Location Models, Archaeological Survey Data and Social Change in Bronze Age Crete." Journal of Anthropological Archaeology United Kingdom 52: 71-86.

Tan, Mely G. 2010. "Masalah Perencanaan Penelitian." In Metode-Metode Penelitian Masyarakat, diedit oleh Koentjaraningrat. Jakarta: PT Gramedia Pustaka Utama.

Tim Peneliti. 2014. "Survei Potensi Arkeologi di DAS Arut dan Identifikasi Temuan Keramik di Rumah Mangkubumi dan Astana Alnursari Kabupaten Kotawaringin Barat Provinsi Kalimantan Tengah”. Laporan Penelitian Arkeologi.” Banjarbaru.

Whitelaw, T., P. Day, Evangelia Kiriatzi, Kilikoglou, dan D. Wilson. 1997. "Ceramic Traditions at EM II B Myrtos, Fournou Korifi.” In Aegaeum, 16:265-74.

Wilson, David E., dan Peter M. Day. 2000. "EM I chronology and social practice: pottery from the early Palace tests at Knossos." Diedit oleh John Bennet dan Peter Liddel. Annual of the British School at Athens 95: 21-63. https://doi.org/10.1017/S0068245400004573.

Yogi, Ida Bagus Putu Prajna. 2017. "Perkembangan Pemukiman di Daerah Aliran Sungai Pawan, Kalimantan Bagian Barat Daya, Abad ke-14 Hingga Abad ke-20 M." Universitas Gadjah Mada. 
PURBAWIDYA: — Vol.10, No. 1, Juni 2021: 45-62 